See Article page XXX.

\section{Commentary: A problem well put is half solved}

\author{
William L. Holman, MD, ${ }^{a}$ Jose A. Tallaj, MD, ${ }^{b}$ and \\ Salpy V. Pamboukian, MD $^{\mathrm{b}}$
}

John Dewey (1859-1952) was an American philosopher, education reformer, and prolific author. His thoughts on the structure of inquiry ${ }^{1}$ are useful for understanding the importance of the article from Zhou and colleagues. ${ }^{2}$ In Logic: The Theory of Inquiry, Dewey addresses the process of inquiry starting with the aphorism "a problem well put is half solved." Quantitive understanding of a problem elevates potential solutions from suggestions to ideas (ie, testable hypotheses). ${ }^{1}$ Zhou and colleagues ${ }^{2}$ do not solve the problem of infection in patients with left ventricular assist devices (LVADs); however, it is a source for ideas.

Infection, bleeding/thrombosis and device malfunction were recognized as potential problems early in the development of LVADs. ${ }^{3}$ Zhou and colleagues ${ }^{2}$ analyzed mortality in LVAD patients with a focus on survival after the first documented infection. They grouped infections based on the work of others as non-VAD, VAD-related, and VADspecific. ${ }^{4}$ The postimplant study intervals (0-90 days, 91-180 days, and $>180$ days) were chosen based on prior published research and the investigators' own experience. The Society of Thoracic Surgeons Interagency Registry for Mechanically Assisted Circulatory Support provided for analysis 12,957 patients enrolled from 2012 through 2017. First infection in the intermediate postimplant

\footnotetext{
From the ${ }^{\mathrm{a} D i v i s i o n}$ of Cardiothoracic Surgery, Department of Surgery, and ${ }^{\mathrm{b}}$ Division of Cardiovascular Diseases, Department of Medicine, University of Alabama at Birmingham, Birmingham, Ala.

Disclosures: Dr Holman serves on the Data Management Committees for Abbott and Medtronic and Dr Pamboukian serves on the Clinical Events Committee for the CARMAT US trial. Dr Tallaj reported no conflicts of interest.

The Journal policy requires editors and reviewers to disclose conflicts of interest and to decline handling or reviewing manuscripts for which they may have a conflict of interest. The editors and reviewers of this article have no conflicts of interest.

Received for publication Nov 9, 2021; revisions received Nov 9, 2021; accepted for publication Nov 9, 2021.

Address for reprints: William L. Holman, MD, Division of Cardiothoracic Surgery, Department of Surgery, University of Alabama at Birmingham, Birmingham, AL 35294 (E-mail: wlholman@uabmc.edu).

J Thorac Cardiovasc Surg 2021; $\mathbf{\square}: 1-2$

0022-5223/\$36.00

Copyright (c) 2021 by The American Association for Thoracic Surgery

https://doi.org/10.1016/j.jtcvs.2021.11.008
}

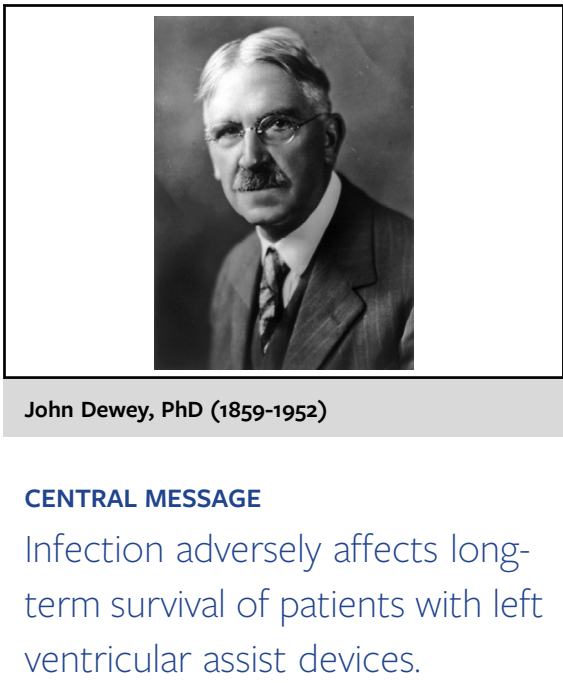

interval (91-180 days) showed the largest increase in the hazard of death. VAD-related and VAD-specific infections showed larger increases in the hazard of death than nonVAD infections. The authors made recommendations for targeting specific classes of infection at certain times after LVAD implant to maximize patient survival. A second recommendation is for early detection and treatment of driveline infections.

Prior research based on the cumulative experience of Interagency Registry for Mechanically Assisted Circulatory Support established the potential for device-related infection to limit patient survival and quality of life. Notably, tethering of implanted pumps to external sources of energy (pneumatic earlier and currently electric) provides a pathway for infection. Fully implantable mechanical circulatory support devices have been challenging to design and use, as demonstrated in clinical trials. The present article by Zhou and colleagues ${ }^{2}$ advances our knowledge of infectious complications based on prospectively gathered data using commonly agreed-upon definitions. As noted by the authors, there are limitations to the data. For instance, they cannot identify the infecting organisms nor do they make a distinction between bacterial and fungal infections. Infections of implanted foreign bodies are often recurrent and may worsen over time. Drivelines are an example of this problem. A simple cutaneous exit site infection may eventually tunnel along the driveline to create abscesses or even infect the exterior of the pump body. Information from this article should be considered in light of information regarding healing and immunological effects of implanted biomedical devices ${ }^{5}$ and the behavior of microbes that cause LVAD infections. ${ }^{6}$ 
Mechanical circulatory support devices in the current era provide long-term ( $>5$ years) survival of some but not all patients. Infection unfortunately limits survival and diminishes quality of life. Incremental improvements based on analyses of cumulative experience (Dr Dewey's ideas rather than suggestions) provide a path to attain the goal of diminishing infections and improving outcomes for LVAD patients.

\section{References}

1. Dewey J. VI: The pattern of inquiry. In: Logic: The Theory of Inquiry. Henry Holt and Company, Inc; 1939:101-19.
2. Zhou S, Yang G, Zhang M, Pienta M, Chenoweth CE, Pagani FD, et al. Mortality following durable left ventricular assist device implantation by timing and type of first infection. J Thorac Cardiovasc Surg. 2022;XX:XX-XXX.

3. US Dept of Health and Human Services. Artificial Heart and Assist Devices: Directions, Needs, Costs, Societal and Ethical Issues. National Institutes of Health; 1985.

4. Hannan MM, Xie R, Cowger J, Schueler S, de By T, Dipchand AI, et al. Epidemiology of infection in mechanical circulatory support: a global analysis from the ISHLT Mechanically Assisted Circulatory Support Registry. J Heart Lung Transpl. 2019;38:364-73.

5. Anderson JM, Rodriguez A, Chang DT. Foreign body reactions to biomaterials. Semin Immunol. 2008;20:86-100.

6. Costerton JW, Stewart PS, Greenberg EP. Bacterial biofilms: a common cause of persistent infections. Science. 1999;284:1318-22. 